\title{
Proctoscopy in infancy with reference to its use in necrotising enterocolitis
}

\author{
TIMOTHY R FENTON, JOHN A WALKER-SMITH, AND DAVID R HARVEY \\ The Hospital for Sick Children, Great Ormond Street, Queen Elizabeth Hospital for Children, \\ and Queen Charlotte's Hospital, London
}

SUMMARY Experience with the fairly simple and safe technique of proctoscopy in an infant using an ordinary auroscope is reported. The use of the auroscope showed the presence of a frank colitis in 13 of 14 consecutive cases of necrotising enterocolitis. A prospective study was made during a 6-month period of 51 infants with diarrhoea referred to a gastroenterology isolation unit; proctoscopic findings that suggested colitis were found in 10. Of these, 3 appeared to have necrotising enterocolitis; 3 had salmonella or shigella dysentery; in 3 of the remaining 4 the findings were localised to the anus, with normal mucosa above. This was attributed to a mild rectal prolapse on straining. There was no correlation between the severity of the diarrhoea and the presence of colitis. Proctoscopy is safe and valuable in the early diagnosis of necrotising enterocolitis. It is also helpful in assessing the progress of the disease.

Necrotising enterocolitis (NEC) in the newborn infant has clinical features which are now well recognised. ${ }^{1-3}$ The diagnostic criteria-namely abdominal distention, bilious vomiting, jaundice, bloody diarrhoea-in the presence of an abdominal $x$-ray film showing intramural or free gas, generally only apply to the more severe cases. More recently attention has been drawn to the presence of free fluid on the abdominal $x$-ray film as having a sinister portent as well as aiding the diagnosis of the disease. ${ }^{4}$ Others have drawn attention to its benign form $^{5}$ and to its occurrence in the age range beyond that seen in a special care baby unit. ${ }^{6}$

A cluster of cases occurred during a brief period in a special care baby unit. While examining an infant with bloody diarrhoea, who was otherwise well, an ordinary paediatric auroscope was used to visualise the rectum. To everyone's surprise this showed the presence of florid colitis. It also proved unexpectedly easy to use the auroscope for this purpose. With the presentation of subsequent cases it became apparent that the finding of colitis on proctoscopy was diagnostic of NEC.

The purpose of this paper is to report the findings on proctoscopy (and its diagnostic value) in patients with: (1) NEC proved by conventional diagnostic criteria as defined above. (2) Children diagnosed as having NEC without the accepted diagnostic $x$-ray features. (3) Patients with acute gastroenteritis.

\section{Methods}

Proctoscopy. Proctoscopy was performed with an ordinary auroscope. It was found that the largest ear piece that could be inserted into the anal canal gave the best view. KY jelly was used sparingly as lubrication in most infants although it did not seem any better than an auroscope moistened with a little water. The auroscope was inserted in a similar fashion to that used in proctoscopy in older patients, with the baby in the left lateral position.

Proctoscopic findings could be divided into three categories. $\mathbf{N}=$ normal pink healthy mucosa. $\mathrm{E}=$ erythema only. $\mathrm{C}=$ frank colitis, an appearance of a red granular mucosa with petechiae or frank contact bleeding.

Patients. The patients were divided into two groups.

\section{Patients with NEC}

Proved NEC. These cases had clinical features consistent with NEC together with the $x$-ray films showing either perforation with free gas under the diaphragm, intramural gas, or free fluid in the peritoneum. In some, the diagnosis was confirmed at laparotomy or necropsy.

Suspected NEC. These cases had the clinical features of NEC, in particular they all had blood in the stools. 
They did not however, have the accepted radiological diagnostic criteria on $x$-ray films.

\section{Acute gastroenteritis}

All the babies with gastroenteritis were admitted during a 6-month period to a gastroenteritis unit at Queen Elizabeth Hospital for Children, London. During this period 275 patients were admitted to the unit. Only infants who were observed to have diarrhoea after admission were included. This amounted to 50 patients in all. Each of them had a routine stool microscopical examination and bacterial culture, as well as electron microscopical examination of the stool for viruses. Twenty-four patients were found to have pathogenic organisms (Table 1), 4 of them having two organisms isolated from the stools concurrently. The negative findings in 26 patients were not unexpected and the recovery rate of organisms from the stool is compatible with other studies. ${ }^{7-8}$

\section{Results}

Fourteen cases of NEC were studied in all. Nine of them had proved NEC. A further 5 did not have the usual diagnostic $x$-ray features. The clinical features in these two groups are listed in Table 2.

Of these 14 cases 13 were shown to have a frank colitis by proctoscopy. One of these had a normal proctoscopy at the onset of NEC, confirmed by the $x$-ray findings of intramural gas. However, he subsequently developed the changes of colitis which persisted throughout the course of his illness. In the remaining case the disease developed acutely on the last day of life after a long illness. The diagnosis was confirmed at necropsy. Proctoscopy 12 hours before death showed only slight erythema.

Each of the 50 infants admitted to the gastroenteritis unit with documented diarrhoea had an episode of gastroenteritis that was more serious than for the other 275 infants. Nineteen of them had a complication of the illness. The complications were: lactose intolerance, cows' milk protein intolerance, multiple food intolerance, hypernatraemia requiring resuscitation with intravenous

Table 1 Micro-organisms isolated from children with gastroenteritis

\begin{tabular}{ll}
\hline & No of patients \\
\hline Enteropathogenic Escherichia coli & 9 \\
Shigella flexneri & 4 \\
Shigella sonnei & 1 \\
Salmonella agona & 3 \\
Campylobacter & 2 \\
Rotavirus & 6 \\
Astravirus & 1 \\
Giardia lamblia & 1 \\
\hline
\end{tabular}

Table 2 Predisposing and clinical features

\begin{tabular}{llll}
\hline & $\begin{array}{l}\text { NEC } \\
\text { proved } \\
n=9\end{array}$ & $\begin{array}{l}\text { Suspected } \\
\text { NEC } \\
n=5\end{array}$ & $\begin{array}{l}\text { Unexplained } \\
\text { colitis } \\
n=4\end{array}$ \\
\hline $\begin{array}{l}\text { Predisposing features } \\
\text { Premature }\end{array}$ & 7 & 3 & 0 \\
$\begin{array}{l}\text { Previous birth asphyxia or } \\
\quad \text { respiratory distress sydrome }\end{array}$ & 4 & 1 & 2 \\
$\begin{array}{l}\text { Previous umbilical vessel } \\
\quad \text { catheterisation }\end{array}$ & 4 & 1 & 0 \\
$\begin{array}{l}\text { Previously breast fed alone } \\
\text { Clinical features and other findings }\end{array}$ & 3 & 2 & 0 \\
$\begin{array}{l}\text { Presented in neonatal period } \\
\text { Vomiting }\end{array}$ & 2 & 5 & 4 \\
$\quad \begin{array}{l}\text { Abdominal distension } \\
\text { Bloody diarrhoea }\end{array}$ & 7 & 0 & 2 \\
Abdominal $x$-ray & 5 & 4 & 1 \\
$\quad$ Normal & 2 & 3 & 2 \\
$\quad \begin{array}{l}\text { Intramural gas } \\
\text { Free fluid }\end{array}$ & 6 & $2 ?$ & $2 ?$ \\
$\quad$ Free gas & 1 & 0 & 0 \\
Diagnosis confirmed at & 0 & 0 & 0 \\
$\quad$ Necropsy & & - & - \\
$\quad$ Laparotomy & 3 & - & - \\
$\quad$ Rectal biopsy & 2 & - & 1 \\
\hline
\end{tabular}

plasma, iron deficiency anaemia, failure to thrive, meningitis, conjunctivitis, febrile convulsion, candidiasis.

Ten of these cases had evidence of colitis on proctoscopy. The findings in these patients are listed in Table 2. Six of these 10 had clear explanations for this finding. Three had either shigellosis or salmonellosis infection, or both; in these conditions colitis is characteristic. In 3 more infants the findings were limited to the anal margin; these findings were attributed to rectal prolapse with associated trauma to the mucosa. Prolapse was actually observed in one infant and the area of reddened friable mucosa corresponded exactly to the area affected by the prolapse. In each of these 3 patients the mucosa above this area was entirely normal unlike that in the NEC patients for whom no upper limit to the abnormal mucosal features could be defined. In 4 of the 10 cases no clear cause for colitis could be established. In 2 of these, and possibly in a third, the history and findings were compatible with mild NEC.

There was no evidence of colitis in the other $\mathbf{4 0}$ cases. Five patients exhibited diffuse erythema only and a further 12 had areas of erythema interspersed with normal mucosa. These findings did not appear to have any diagnostic or clinical significance. Blood was seen in the stools in 5 of the 10 patients with colitis and in only 1 of the other 40 infants. Pus was seen in the stools of 2 patients, each of whom had a colitis.

The mean maximum percentage weight loss in the first week was $4.06 \%$. In the patients with colitis the mean maximum percentage weight loss was $3 \cdot 28 \%$, therefore these cases did not appear to have more 
severe diarrhoea. Neither of the patients who required resuscitation with plasma on arrival had evidence of colitis. Indeed, only one patient with colitis had any of the complications listed above and he suffered from diarrhoea and meningitis with Escherichia coli isolated both from stool and cerebrospinal fluid.

\section{Discussion}

The proctoscopic findings of colitis in NEC reported in this paper have not previously been reported. It was concluded that the finding of colitis on proctoscopy, together with bloody diarrhoea and abdominal distension in the appropriate clinical setting were sufficient criteria on which to base a diagnosis of NEC.

Surgery in NEC should be reserved for its surgical complications. $^{2}$ However, it is recognised that prompt treatment (stopping oral feeds, maintaining fluid balance with intravenous fluids, with or without administration of broad spectrum antibiotics) is necessary to prevent such complications. Early diagnosis is thus particularly important.

The differential diagnosis of NEC in the neonatal period is limited. Shigellosis or salmonellosis must be considered but can be distinguished by stool cultures. Chronic inflammatory bowel disease occurs more often in older infants but would be difficult to distinguish at this age from NEC. Certainly the proctoscopic features of one 4-month-old infant with ulcerative colitis (personal observation) were indistinguishable from those of NEC. Pseudomembranous colitis, if it occurs in this age group, should be easily distinguishable by its membrane. Graft versus host reaction, with bloody diarrhoea in an infant with severe combined immunodeficiency, also exhibited proctoscopic findings identical with those in NEC (personal observation). It is claimed that colitis can also be found with cows' milk protein intolerance, ${ }^{9-10}$ but this was not found to be so in the 2 patients with cows' milk protein intolerance in this study. These diagnoses were excluded in the 14 cases diagnosed here as NEC.

The method described in this paper is simple, requiring no equipment other than that which is normally to be found on a paediatric ward. It was not found necessary to insufflate the rectum to obtain a good view although this would be possible using the normal insufflator supplied as an attachment for the auroscope. In our experience this technique is safe, with no mortality or morbidity arising from it. One child did subsequently suffer a perforation but this was at the splenic flexure and could not be attributed to the proctoscopy. It is unsuitable for older infants $(>1$ year) as the increase in size of the buttocks prevents the short barrel of the auroscope penetrating much beyond the anal margin. This could lead to a false-positive diagnosis of colitis as this area is sometimes damaged by the rectum prolapsing, as previously described.

It is not clear why one baby with NEC diagnosed by $x$-ray, proved at necropsy, did not show changes of colitis. There are two possible explanations. Firstly, the infant deteriorated very rapidly, dying within 24 hours, thus he might not have had time to develop a distal colitis. Secondly, the disease may be similar to Crohn's disease in which it is known that disease may be present in the submucosal region on biopsy when the mucosa appears unaffected on endoscopy. The diagnosis may be assisted in all cases of NEC by taking a rectal biopsy, as in one infant who presented to the gastroenteritis unit.

Santulli et $a .^{2}$ bemoaned the lack of a good clinical marker for NEC as they felt it led to considerable under-reporting of the disease; our experience would agree with this. We believe that the proctoscopic finding of colitis combined with the clinical features consistent with NEC are adequate criteria on which to base the diagnosis of NEC both in late and early stages of the disease. Indeed, the absence of colitis has been found a useful discriminator in other conditions-for example, the normal proctoscopic findings in 2 infants with intussusception who presented with bloody diarrhoea only. It was also found useful to check on the proctoscopic findings from time to time during the course of the child's illness. In NEC the severity of the colitis reflects the severity of the disease and influences the choice on whether or not to reintroduce oral feeding

We thank our colleagues who allowed us to examine patients under their care, particularly Professor C B S Wood, Dr A D Jackson, Mr J A S Dickson, Miss V Wright, and Dr W C Marshall.

\section{References}

1 Franz I D, III, L'Heureux P, Engel R R, Hunt C E. Necrotizing enterocolitis. J Pediatr 1975; 86: 259-63.

2 Santulli T V, Shullinger J T, Heird W C, et al. Acute necrotizing enterocolitis in infancy: a review of 64 cases. Pediatrics 1975; 55: 376-87.

3 Mizrani A, Barlow O, Berdon W, Blanc W A, Silverman W A. Necrotizing enterocolitis in premature infants. J Pediatr 1975; 66: 697-706.

4 Rabinowitz J G, Siegle R L. Changing clinical and roentgenographic patterns of necrotizing enterocolitis. AJR 1975; 126: 560-6.

5 Richmond J A, Mikity V. Benign form of necrotizing enterocolitis. $A J R$ 1975; 123: 301-6.

6 Polin R A, Pollack P F, Barlow B, et al. Necrotizing enterocolitis in term infants. J Pediatr 1976; 89: 460-2. 
7 Harries J T. The problems of bacterial diarrhoea. In: Elliott K, Knight J, eds. Acute diarrhoea in childhood. Ciba Foundation Symposium No 42. Amsterdam: Elsevier/Excerpta Medica/North-Holland, 1976: 3.

8 Tripp J T, Wilmers M J, Wharton B A. Gastroenteritisa continuing problem in child health in Britain. Lancet 1977; ii: 233-6.

9 Walker-Smith J A. Diseases of the small intestine in childhood, first edition. Tunbridge Wells: Pitman Medical, 1975: 95.
10 Grabowski J D. Gastrointestinal problems in the infant. Philadelphia: Saunders, 1975: 664.

Correspondence to Dr T R Fenton, Department of Child Health, Institute of Child Health, 30 Guilford Street, London WCIN 1EH.

Received 20 November 1979

\section{Breath-holding attacks-Dickens 1864}

I wonder if the first description of breath-holding attacks in the toddler age group should be attributed to Charles Dickens? In chapter 16 of Our mutual friend, published in 1864-5, is described a cottage where Mrs Betty Higden, a poor widow, is fostering Johnny (pet name Toddles) who is an orphan. The child's age is not given but his speech is described as being 'little more than monosyllabic'. An elderly couple who are looking for a child to adopt approach the cottage just as Johnny overbalances, topples into the street, and begins to cry. There follows general embarrassment and confusion, which ' ... it was impossible to explain on account of the orphan's holding his breath, a most terrific proceeding, superinducing in the orphan lead-colour rigidity and a deadly silence, compared with which his cries were music yielding the height of enjoyment. But as he gradually recovered ... smiling peace was gradually wooed back to Mrs Betty Higden's home'. This vivid description suggests that breath-holding attacks were well known to Dickens, and that he knew they were more alarming than serious.

Paediatric interest is maintained. Later in the novel the child develops a different, more serious illness. The foster-mother refuses to let him go away until she is told "we want to move Johnny to a place where there are none but children; a place set up on purpose for sick children; where the good doctors and nurses pass their lives with children, talk to none but children, touch none but children, comfort and cure none but children' and so he is admitted to 'the Children's Hospital' in London. Was this The Hospital for Sick Children, Great Ormond Street, which had been founded by Charles West in 1851,13 years before the novel was written? 